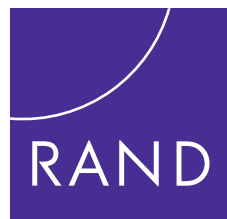

HEALTH

\title{
Weight Loss Surgery Is More Effective Than Diet and Exercise in Helping Severely Obese People Lose Weight
}

RAND RESEARCH AREAS

ENERGY AND ENVIRONMENT HEALTH AND HEALTH CARE

INTERNATIONAL AFFAIRS

NATIONAL SECURITY

POPULATION AND AGING

PUBLIC SAFETY

SCIENCE AND TECHNOLOGY

SUBSTANCE ABUSE

TERRORISM AND

HOMELAND SECURITY

TRANSPORTATION AND INFRASTRUCTURE

WORKFORCE AND WORKPLACE
The prevalence of obesity in the United States and elsewhere is rising precipitously: A 1999-2002 survey estimated that 30 percent of the U.S. population met the criteria for obesity, a body mass index (BMI — a ratio of weight to height) of 30 or higher (those with a BMI of 40 or over are considered severely obese). ${ }^{1}$ The health consequences of obesity are considerable, yet weight loss of just 5 to 10 percent may lower the risks. The increasing prevalence of obesity has intensified interest in surgical treatments to achieve weight loss, also known as bariatric surgery. These procedures can reduce stomach capacity or adjust intestinal length to restrict food consumption or reduce the calories and nutrients the body can absorb. With a reported rise in the number of procedures-and complications - researchers at the Southern California Evidence-Based Practice Center, which is funded by the Agency for Healthcare Research and Quality and housed at RAND, recently examined the effectiveness and risks of this surgery by analyzing nearly 150 published studies, focusing on the most commonly performed procedures.

- In severely obese individuals, surgery resulted in a weight loss of 45 to 65 pounds, which was maintained up to ten years.

- For individuals with an average BMI of 40 or more, surgery resulted in greater weight loss than did nonsurgical treatments, including prescription medications and diet advice. Evidence is inconclusive for the effectiveness of surgery for those who are less severely overweight.

- Patients who undergo gastric bypass surgery - which limits nutrient absorption and is the most common form of weight loss surgery - typically lose about 20 pounds more than those who undergo vertical banded gastroplasty, which restricts food consumption.

- Surgery is associated with improvements in some obesity-related conditions such as hypertension, diabetes, elevated cholesterol, and sleep apnea.

- More than 20 percent of those who undergo bariatric surgery experience complications. Although most are minor, some can be serious. The overall death rate from the procedures was less than 1 percent.

A significant learning curve was noted among surgeons who performed the procedures: Complication rates and patient deaths were significantly higher among surgeons who had performed fewer than 50 of the surgeries.

- Too few children and adolescents have undergone the surgery to allow assessment of the effectiveness or safety of bariatric surgery for these age groups.

${ }^{1}$ For example, a person who is 5 feet 10 inches and weighs 209 pounds has a BMI of 30; a 5 foot 10 inch person who weighs 280 pounds has a BMI of 40 .

This fact sheet is based on MA Maggard, LR Shugarman, M Suttorp, M Maglione, HJ Sugarman, EH Livingston, NT Nguyen, Z Li, WA Mojica, L Hilton, S Rhodes, SC Morton, and PG Shekelle, "Meta-Analysis: Surgical Treatment of Obesity," Annals of Internal Medicine, Vol. 142, 2005, pp. 547-559. 

summarize published, peerreviewed documents or a body of published work. The RAND Corporation is a nonprofit research organization providing objective analysis and effective solutions that address the challenges facing the public and private sectors around the world. RAND's publications do not necessarily reflect the opinions of its research clients and sponsors. RAND ${ }^{\circledR}$ is a registered trademark.

RAND Offices Santa Monica - Washington - Pittsburgh - New York - Doha - Berlin - Cambridge - Leiden 
THE ARTS

CHILD POLICY

CIVIL JUSTICE

EDUCATION

ENERGY AND ENVIRONMENT

HEALTH AND HEALTH CARE

INTERNATIONAL AFFAIRS

NATIONAL SECURITY

POPULATION AND AGING

PUBLIC SAFETY

SCIENCE AND TECHNOLOGY

SUBSTANCE ABUSE

TERRORISM AND HOMELAND SECURITY

TRANSPORTATION AND INFRASTRUCTURE

WORKFORCE AND WORKPLACE
This PDF document was made available from www.rand.org as a public service of the RAND Corporation.

This product is part of the RAND Corporation research brief series. RAND research briefs present policy-oriented summaries of individual published, peerreviewed documents or of a body of published work.

The RAND Corporation is a nonprofit research organization providing objective analysis and effective solutions that address the challenges facing the public and private sectors around the world.

\section{Support RAND}

$\underline{\text { Browse Books \& Publications }}$

Make a charitable contribution

For More Information

Visit RAND at www.rand.org

Explore RAND Health

View document details

Limited Electronic Distribution Rights

This document and trademark $(s)$ contained herein are protected by law as indicated in a notice appearing later in this work. This electronic representation of RAND intellectual property is provided for noncommercial use only. Permission is required from RAND to reproduce, or reuse in another form, any of our research documents for commercial use. 